\title{
THE USE OF AHP WITHIN GIS FOR DESTRUCTED AREAS IN DAMASCUS, SYRIA
}

\author{
Mohamad Khalil ${ }^{1}$, J. Satish Kumar ${ }^{2}$ \\ ${ }^{1}$ Department of Geography, Faculty of Arts \& Human Sciences, Damascus University, Damascus, Syria - mk7682@ srmist.edu.in \\ ${ }^{2}$ Department of Civil Engineering, SRM institute Science and Technology, Chennai India - sathishj1@ srmist.edu.in
}

KEY WORDS: Remote Sensing, Geographic Information System, Analytic Hierarchy Process, Consistency Ratio, Compatibility Index, Random index.

\begin{abstract}
:
War This is a word that everyone fears as a result of the violence and devastation it leaves, as there have been many wars around the world that have greatly affected the lives of civilians. Infrastructure, homes, hospitals, and other public facilities have been damaged and partially or largely destroyed. Syria is a country in south-western Asia, located near the Mediterranean Sea, between Lebanon and Turkey. Syria is which suffered from war for more than 10 years and still. This is a study on the city of Damascus, the capital of the Syrian Arab Republic, many of its areas were destroyed by this war. throughout the war, more than 55\% of the Syrian population in urban areas and rural areas were affected by the massive aerial bombardment and fighting inside towns, cities, and old neighbourhoods. This study aims to identify the most affected areas in the Syrian capital, Damascus, by analysing two satellite images from the satellite Sentinel using a program SNAP and determining the most appropriate areas for reconstruction in Damascus through the AHP analysis method using a program ArcGIS. Where 6 basic criteria were set to carry out the analysis it's elevation, slope, soil, water network, road network, and land use, land cover. The results were classified into five classes in terms of suitability for reconstruction, not suitability, low suitability, moderate suitability, high suitability, very high suitability, and to determine the percentage of each classification.
\end{abstract}

\section{INTRODUCTION}

Disasters like, earthquakes, floods, volcanoes, and wildfires have always existed as a result of the disturbances of nature. The power of disasters could be so intense and violent that they become another factor of destruction to many living things. However, this has been subjected to change since humans proved to be able to adjust damage's balance, recovery with reconstruction (Del Moral, Walker, 2007). "A Disaster is an event or series of events, which gives rise to casualties and damage or loss of properties, infrastructure, environment, essential services or means of livelihood on such a scale which is beyond the normal capacity of the affected community to cope with." (Leonard, 2018). "Disaster can be defined as a situation in which the ordinary ways of life are disrupted, and extreme extraordinary emergency interventions are called for to save human lives and the surroundings. Natural disasters can be sometimes linked to humans as they can play a role in making them occur, like wars". (UNISDR, Reduction, 2009).

"This never-ending war, which lasted more than 10 years, resulted in the killing of more than 500 thousand people, and coercive more than half of the population to escape their areas in search of safety. A major deterioration in residential buildings, the number of completely destroyed buildings in Eastern Ghouta, Damascus, reached 9353, in addition to 13,661 severely destroyed buildings and 11,122 partially destroyed, with a total of 34,136 damaged buildings." GIS is also used to fix damaged information, post-disaster census information, and evaluate sites for reconstruction. GIS also enables different types of data to be merged using models. It permits different types of spatial data to be integrated with non-spatial data and feature data and to be used as useful information in various phases of disaster management.

LSA is a GIS-based multi-criteria evaluation process applied to determine the suitability of a specific area for particular land use and to estimate the potential of land for alternative land uses considering wide ranges of criteria based on environmental, social, and economic factors. Appropriate handling of such broad and heterogeneous maps requires applying a flexible tool (Jafari, Zaredar, 2010). Thus, GIS has been increasingly used as an important spatial decision support system for land suitability analysis (Mendas, Delali 2012).

RS and GIS application has become an advanced and very successful tool in disaster management, as we have our location monitoring software and requirements for risk mitigation and monitoring ranked high in the planning of new satellites.

\section{MATERIALS AND METHOD}

\subsection{Study Area}

Syria is a country in south-western Asia, located near the Mediterranean Sea, between Lebanon and Turkey. It is an Arab country. Syria's political and economic significance in history is associated with its position at the crossroads of three continents and many different cultures. Its strategic geographic location is what made Syria a destination for trade between many countries 
in the Middle East. Consisting of 14 governorates, the capital and largest city of which is Damascus.

This is a study on the city of Damascus, the capital of the Syrian Arab Republic. Damascus is located on a large plain along with the border of the Anti-Lebanon mountain range where the River Barada flows. Damascus was a very remarkable cultural and commercial centre due to the value of its geographical location at the crossroads of orients. Damascus' location also serves as the centre of a large oasis in the desert. However, Al-Ghouta makes further problems because of its feeble ecological environment. Ungoverned rapid urbanization was the main factor in the destruction of Al-Ghouta, which has granted the city agriculture and an ecological balance for the past thousands of years.

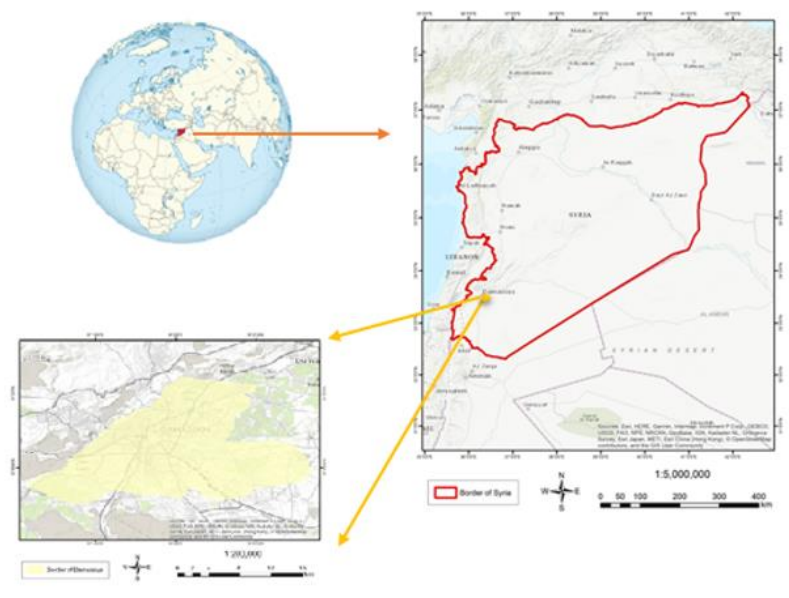

Figure 1: Map of the study area

\subsection{Methodology}

In this study, the Sentinel-2A polar-orbiting satellites were used. Both Multispectral Instruments (MSI) on-board are now operational: Sentinel-2A was launched on 23 June 2015 and Sentinel-2B followed on 7 March 2017. A free, full, and open data policy has been adopted by the EU for the Copernicus Programme, which foresees access by all users to the Copernicus Sentinels core products. The radiometric, spectral, and spatial characteristics of the bands used in this study are specified in the User Handbook (ESA, Sentinel-2 User Handbook, 2019). A temporal examination provided Level-1C Sentinel-2 images that were typically geo-located within two pixels of each other $(20 \mathrm{~m})$ which is within the stated quality requirements for absolute geo-location (ESA, Sentinel-2 MSI Technical Guide, 2017). Sentinel-2 Level 1 datasets (zone 37, sub-tile SXG, and SXH) were downloaded from the ESA official website Copernicus Open Access Hub (Sentinel's Scientific Data Hub, 2019). The Copernicus Services Data Hub is access to Copernicus Sentinels data dedicated to Copernicus Services and European Institutions. Copernicus Sentinel-2 data are systematically processed to L1C products and made available online between 2 and $12 \mathrm{~h}$ from sensing (on average, 7 $\mathrm{h}$ after sensing) in the Copernicus Open Access Hub and Copernicus Services Data Hub. Only images with low cloud coverage $(<20 \%$ over the region of study) were considered and downloading time was generally around $0.5 \mathrm{~h}$. At least two images with the same orbit track and the same coverage are required for change detection, namely, the reference image (preevent) and the target image (co-event), respectively. The reference image was selected as the latest available image prior to the event with minimum cloud coverage. The scenes were selected carefully with two Sentinel-2 satellite images before (20 August $20152 \mathrm{~A}$ ) and two scene-captures during or immediately following (27 October 2020 2A) the event. Is shown in figure $2-3$.

Band math approach has been accomplished using the SNAP software A common architecture for all Sentinel Toolboxes is being jointly developed by Brockmann Consult, Array Systems Computing and $\mathrm{C}-\mathrm{S}$ called the Sentinel Application Platform (SNAP). (version 8.0.3).

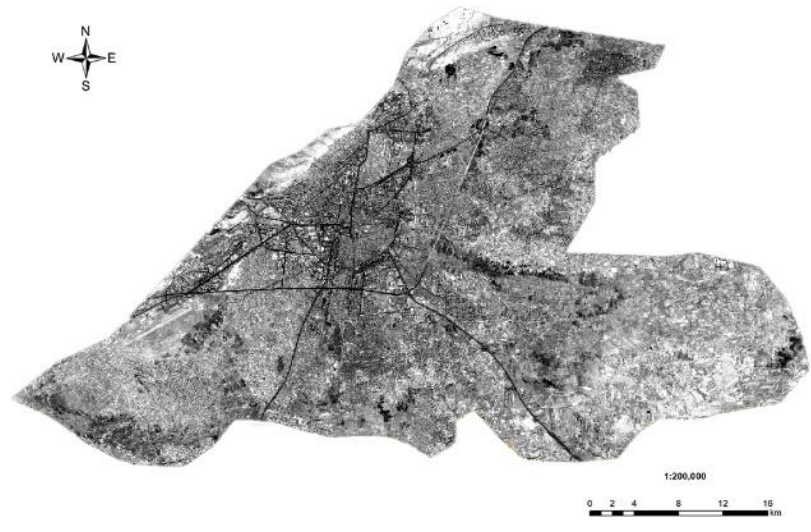

Figure 2: Damascus, 20 August 2015 2A, 1 Meter Sentinel image.

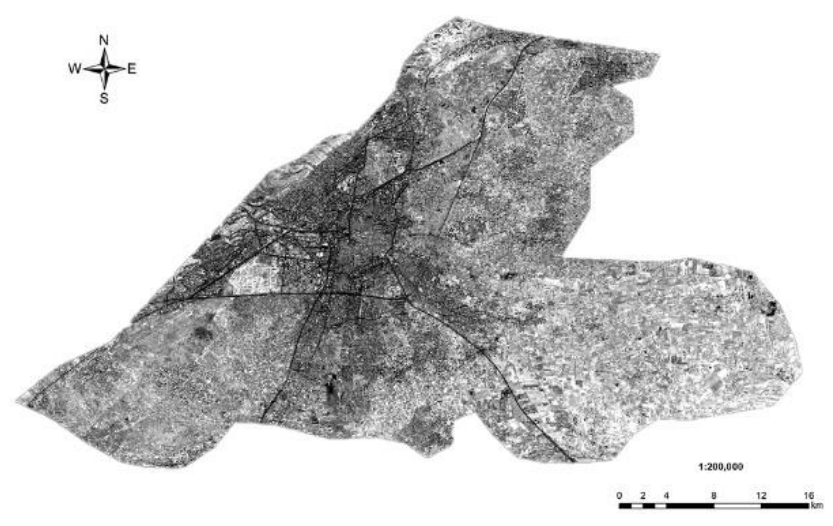

Figure 3: Damascus, 27 October 2020 2A, 1 Meter Sentinel image.

\subsubsection{AHP analysis according to Thomas Saaty:}

"To analyze complex fuzzy problems, this method was proposed by Thomas Saaty based on the analyses in the human mind. Analytic Hierarchy Model is one of the most comprehensive models designed for multi-criteria decisionmaking. It provides a hierarchical formulation for problems and lets quantitative and qualitative criteria be considered in the problem. It includes different alternatives in decision making and analyses the vulnerability on the criteria and sub-criteria". 
"AHP is generally used for estimating large numbers of criteria and solving multi-criteria problems. It enables decision-makers to use the testability of this model in solving different problems regardless of any collection they are from. Since AHP does not work based on probability, the last results are transparent. On the other hand, paired comparisons facilitate the evaluation of several alternatives with different criteria from different groups as an integrated part of this process".

"AHP is based on paired comparisons and simplifies judgment and calculation. It is also showing the compatibility and incompatibility of a decision as a vital advantage for this multicriterion decision-making technique founded on powerful theoretical frameworks (Sarvar et al, 2011a).

All comparisons in this hierarchical analysis process are done in pairs thus, decision-makers may have the opportunity to compare verbal judgments so that if element $i$ is compared to element $j$, the decision-maker may decide on the importance of $i$ over $j$ according to table 1 offered by Thomas Saaty".

"AHP is based on paired comparisons and facilitates judgment and calculation. It also displays the compatibility and incompatibility of a decision as a vital advantage for this multicriterion decision-making technique founded on powerful theoretical frameworks".

"When the preference of the criteria over each other is defined, the Consistency Ratio of the system (CR) should not exceed 0.1 where $\mathrm{CR}$ is obtained from dividing Compatibility Index (CI) by average consistency ratio index (RI) i.e., $\mathrm{CR}=\mathrm{CI} / \mathrm{RI}$ where $\mathrm{RI}$ is provided by Saaty in 1991 for different sizes and CI is obtained from Eq (1).

$$
C I=\frac{\lambda_{\max }-n}{n-1}
$$

Where $\mathrm{n} i$ the number of criteria, $\lambda_{\max }$ is the maximum Eigenvalue. Revision on the weights will be necessary in case the CR exceeds 0.1" (Sarvar et al, 2011b).

\begin{tabular}{cc}
\hline Definition & Intensity of relative importance \\
\hline Extremely Preferred & 9 \\
Very strongly Preferred & 7 \\
strongly Preferred & 5 \\
Moderately Preferred & 3 \\
Equally Preferred & 1 \\
intermediate values between & $2,4,6,8$ \\
\hline
\end{tabular}

Table 1. The Fundamental Scale for Making Judgments

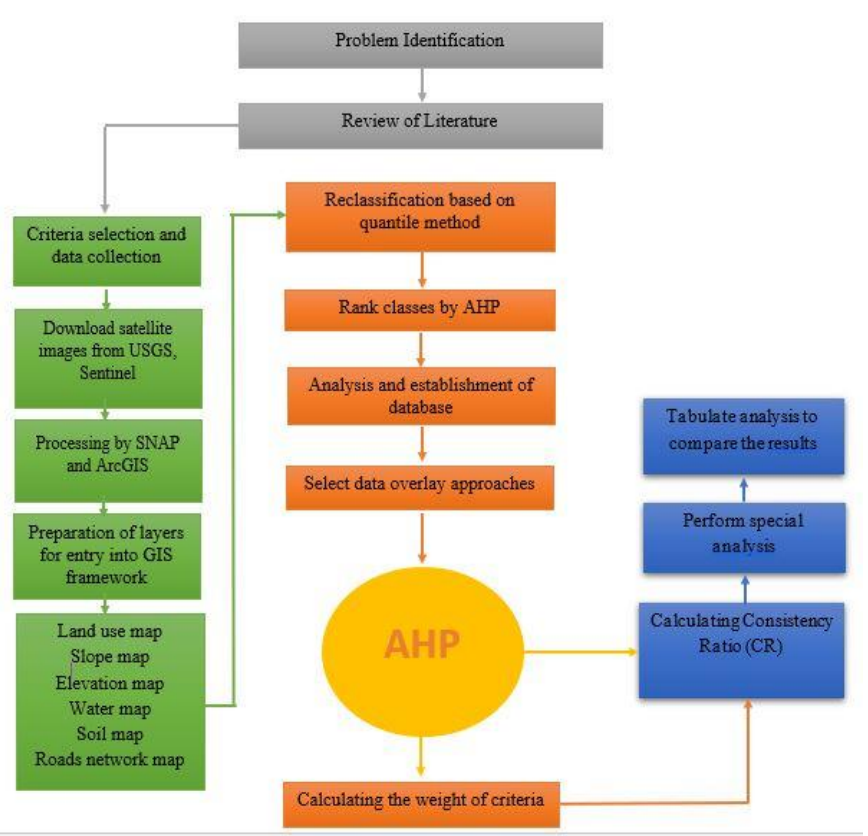

Figure 4: Methodology used in this research.

\section{RESULT AND DISCUSSION}

By using two satellite images on different dates and making an analysis of Band math to determine the destruction areas through SNAP software, the result was a satellite image showing the location of the destruction in the study area. Where the destruction was concentrated in Jobar, Zamalka, Al Masani, Qaboun, Ein Terma, Arbin, Harasta, Saqba, Jammura, Misraba, Duma (REACH, 2019). On average, 5 buildings per hectare are classified as damaged or destroyed within the Eastern Ghouta suburbs. This ranges from $7-14$ buildings per ha in the 5 most damaged neighbourhoods. damage density is highest in Jobar neighbourhood on the edge of Damascus city, where density is 14.8 buildings damaged or destroyed per hectare. Is shown in figure 5 .

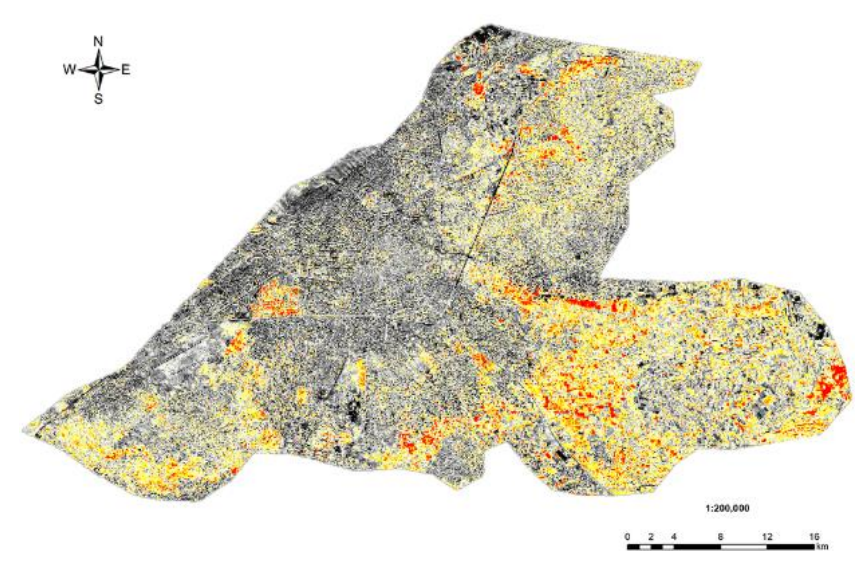

Figure 5: Change between before the war and after the war, 1 Meter Sentinel image. 
The red colour symbolizes the most damaged areas, and the yellow colour symbolizes the least damaged areas.

Using AHP makes it possible to reach a relative result through the relevant factors after the construction of a pairwise comparison matrix. The selected six criteria were: slope, elevation, soil, road network, water network, and land use, after that there is use a scale ranging from 1 over 9,1 means both criteria have the same significance which equals 9 and that is very important. For example, land use is significantly more important than slope.

To decide the definite weight of each factor, as a result of the comparison between criteria, is done through the usage of the geometric mean method. Next, the factors were rearranged according to their weights with suggested using a raster calculator to produce a suitability map. The result of the pairwise comparison matrix obtained is shown in Table 2.

\begin{tabular}{|c|c|c|c|c|c|c|c|c|}
\hline Factors & Slope & Blevation & Water & Soil & Roads & $\begin{array}{l}\text { Land } \\
\text { use }\end{array}$ & Weight & Weightage \\
\hline Slope & 1 & 2 & 3 & 5 & 7 & 9 & 0.437 & 0.204 \\
\hline Elevation & $1 / 2$ & 1 & 3 & 2 & 3 & 5 & 0.458 & 0.214 \\
\hline Water & $1 / 3$ & $1 / 3$ & 1 & 5 & 5 & 7 & 0.397 & 0.186 \\
\hline Soil & $1 / 5$ & $1 / 2$ & $1 / 5$ & 1 & 9 & 9 & 0.378 & 0.177 \\
\hline Roads & $1 / 7$ & $1 / 3$ & $1 / 5$ & $1 / 9$ & 1 & 7 & 0.278 & 0.130 \\
\hline Land use & $1 / 9$ & $1 / 5$ & $1 / 7$ & $1 / 9$ & $1 / 7$ & 1 & 0.184 & 0.086 \\
\hline Total & 2.287 & 4.366 & 7.542 & 13.222 & 25.142 & 38 & 2.132 & 1 \\
\hline
\end{tabular}

Table 2: The pairwise comparison matrix

Consistency check:

"Consistency of the formed eigenvector matrix for AHP needs to be evaluated. The required level of consistency is evaluated using the following index:"

$$
C R=\frac{C I}{R I}
$$

\section{Where: \\ $\mathrm{CR}$ the consistency ratio \\ CI the consistency index}

"RI the random index:"

"In table 3 Random consistency Index (RI) are tabulated. Thus, in this study the RI $=1.24$. The acceptable $\mathrm{CR}$ must be $<0.1$. CI is calculated using Eq (1) where calculated $\lambda \max =11.678$. RI values are given in specific tables."

$\begin{array}{ccccccccccc}\mathrm{N} & 1 & 2 & 3 & 4 & 5 & 6 & 7 & 8 & 9 & 10 \\ \mathrm{RI} & 0 & 0.0 & 0.58 & 0.90 & 1.12 & 1.24 & 1.32 & 1.41 & 1.45 & 1.51\end{array}$

Table 3: Determination of the random index

"Eventually, calculated consistency ratio is 0.915 that is lower than the threshold 0.1 , the weights' consistency is affirmed."

\begin{tabular}{|c|c|c|c|}
\hline Factors & Weight & Rink & Over All \\
\hline \multicolumn{4}{|c|}{ Slope } \\
\hline $1-2$ & 0.204 & 4 & 0.816 \\
\hline $2-3$ & & 3 & 0.612 \\
\hline $3-5$ & & 2 & 0.408 \\
\hline$>5$ & & 1 & 0.204 \\
\hline \multicolumn{4}{|c|}{ Elevation } \\
\hline $650-700$ & 0.214 & 4 & 0.856 \\
\hline $700-750$ & & 3 & 0.642 \\
\hline $750-800$ & & 2 & 0.428 \\
\hline$>800$ & & 1 & 0.214 \\
\hline \multicolumn{4}{|c|}{ Water bodies } \\
\hline High & 0.186 & 2 & 0.372 \\
\hline Medium & & 3 & 0.558 \\
\hline Low & & 4 & 0.744 \\
\hline Very Low & & 5 & 0.93 \\
\hline \multicolumn{4}{|c|}{ Soil } \\
\hline Gypsic Xerosol & 0.177 & 1 & 0.177 \\
\hline Lithosols Soil & & 2 & 0.354 \\
\hline \multicolumn{4}{|c|}{ Roads Network } \\
\hline $56.5-146.1$ & 0.130 & 4 & 0.52 \\
\hline $146.1-209.0$ & & 3 & 0.39 \\
\hline $209.0-276.6$ & & 2 & 0.26 \\
\hline $276.6-400.8$ & & 1 & 0.13 \\
\hline \multicolumn{4}{|c|}{ Land use } \\
\hline Agricultural & 0.086 & 4 & 0.344 \\
\hline Urban Lands & & 3 & 0.258 \\
\hline Roads & & 2 & 0.172 \\
\hline Rocks & & 1 & 0.086 \\
\hline
\end{tabular}

Table 4: The rating of the six criteria selected based on literature review and weights.

\begin{tabular}{|c|c|c|c|c|c|}
\hline Criteria & Weights & $\lambda \max$ & CI & RI & CR \\
\hline Slope & 0.204 & \multirow{6}{*}{11.678} & \multirow{6}{*}{1.135} & \multirow{6}{*}{1.24} & \multirow{6}{*}{0.915} \\
\hline Elevation & 0.214 & & & & \\
\hline Water & 0.186 & & & & \\
\hline Soil & 0.177 & & & & \\
\hline Roads & 0.130 & & & & \\
\hline Land use & 0.086 & & & & \\
\hline
\end{tabular}

Table 5: The computed values of weights, CI, RI, and CR

As shown in Table 5, the six GIS layers representation the physical criteria were subjected to a GIS analysis to select the optimum location for the reconstruction in the study area based on these criteria. All maps (Slope of Degree, Elevation Map, Water Density, Soil Map, Roads Density, Land use), the following spatial data techniques were used:

\section{Converted to a raster format \\ Slope derivation \\ Raster reclassification \\ Raster calculation}

Physical Criteria Analysis:

For evaluating land suitability, six criteria including elevation, slope, soil, water density, roads density, land use, were selected based on relevant literature review (Bozdağ et al, 2016a).

DEM uploaded from USGS (United States Geological Survey) website was used with a resolution of $5 \times 5 \mathrm{~m}$, from this DEM slope and elevation map were made (Achour et al, 2017a). 
Elevation map: provides a colorized representation of Elevation. The elevation map was subdivided into five classes: (I) 612-650, (ii) 650-700, (iii) 700-750, (iv) 750-800, and (v) $>800$ (Bozdağ et al, 2016b). The red area is the highest elevation on the summit of Mount AL sheik, at 2,814 meters above sea level. The attitude extends to the lowest point as far as Eastern Ghouta, which is in green colour, with a height of 612 meters above sea level. Is shown in figure 6 .

Slope map: provides a colorized representation of slope, generated dynamically using server-side slope function on Terrain service. The slope angle map was subdivided into five classes of inclination: (I) $0-1^{\circ}$, (ii) $1-2^{\circ}$, (iii) $2-3^{\circ}$, (iv) $3-4^{\circ}$, and (v) $>5^{\circ}$ (Achour et al, 2017b). The degree of slope steepness is depicted by light to dark colours - flat surfaces as green, shallow slopes as light yellow, moderate slopes as light orange, and steep slopes as red brown. Is shown in figure 7.

Soil map: Soil suitability the type of soil is one of the most important factors for land suitability. Soil behaviour helps to estimate the soil performance for agricultural production. Thus, when deciding on the suitability of land, it is necessary to know the soil types (Akinc1, 2013). 20\% of Syria's area is gypsum soil. This soil contains a high percentage of gypsum material $(10-35 \%)$ near the surface, and (50-70\%) in depths for shallow soils, while this percentage is $15 \%$ in deep soils, which are poor. It has a very organic matter and a pale-yellow colour, and the consistency of the upper horizon is weak, and the presence of stucco makes it unfit for agriculture. In addition to Lithosols Soil. Is shown in figure 8 .

\begin{tabular}{ll}
\hline Type & Spaces \\
\hline Gypsic Soil & $197.645 \mathrm{~km} 2$ \\
\hline Lithosols Soil & $82.5287 \mathrm{~km} 2$ \\
\hline
\end{tabular}

Table 6: Spaces of soil types

Water density: Drainage density is the total length of the drainage system per unit area of the watershed (Tairi, 2019). There are two rivers in Damascus, the Barada River, which springs from the Barada spring northwest of Damascus and empties into Lake Al-Otaiba in the southeast, and the Al-Awaj River originates from Al-Sheikh. This density was calculated by dividing the total length of the hydrographic network of $72 \mathrm{~km}$ for the Barada River and $70 \mathrm{~km}$ for the Al-Awaj River by the total catchment area of $18,032 \mathrm{~km} 2$ (Arraf, 2019). It is shown in figure 9 .

Road density: The neighbourhoods and regions of Damascus are linked by a network of modern and international roads that penetrate the city from all directions, intersecting road lines in all directions, as well as a railway line. Is shown in figure 10 .

Land use: The Landsat 8 satellite image from the USGS website has been relied on as an alternative to fieldwork due to the ongoing military a cations in the country The area of each use in the study area was calculated using ArcMap, The 1:200,000 scale topographical maps were digitized and all the criteria maps were prepared from the related maps by scanning, digitizing, and geocoding the relevant information. Where it was classified into the cemetery, commercial, construction, farm, farmland grass, greenfield, industrial, military, pitch, residential, building. Is shown in Table 7. Is shown in figure 11.

\begin{tabular}{|l|l|l|}
\hline Types & Space m2 & Percentage \\
\hline Cemetery & 162524.2846 & 0.73 \\
\hline Commercial & 112895.5608 & 0.51 \\
\hline Construction & 63564.03143 & 0.28 \\
\hline Farm & 5393686.986 & 24 \\
\hline Farmland & 5393686.986 & 25 \\
\hline Grass & 5125.743205 & 0.02 \\
\hline Greenfield & 10343.06017 & 0.04 \\
\hline Industrial & 165174.661 & 0.74 \\
\hline Military & 312032.4839 & 1.41 \\
\hline Pitch & 85125.39041 & 0.38 \\
\hline Residential & 10326169.63 & 46.8 \\
\hline
\end{tabular}

Table 7: Spaces of Land use and cover types

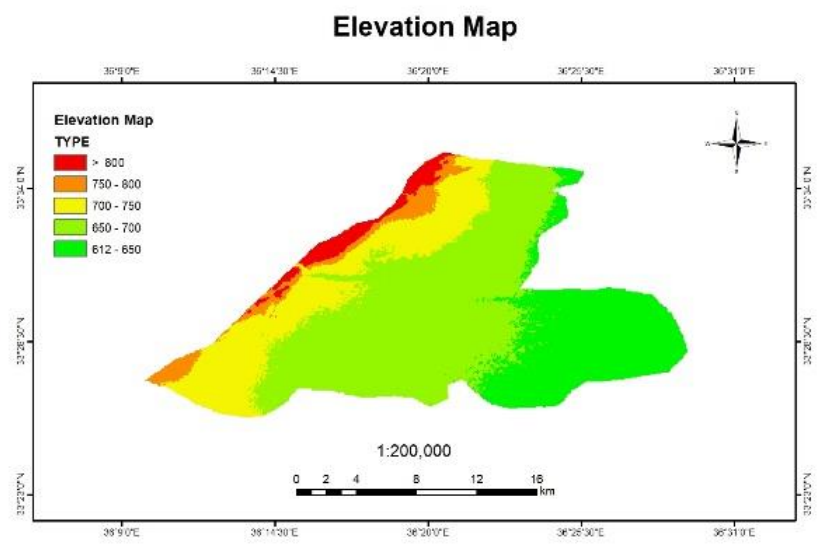

Figure 6: Elevation map

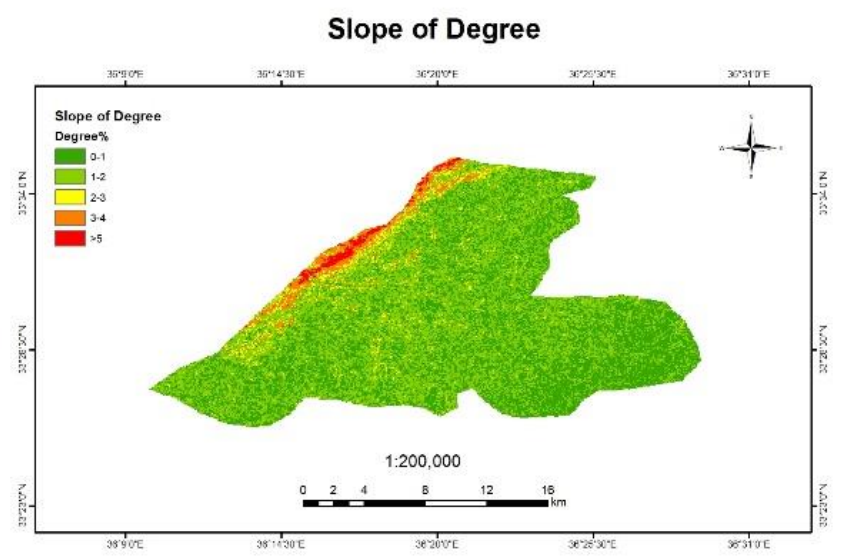

Figure 7: Slope of Degree 


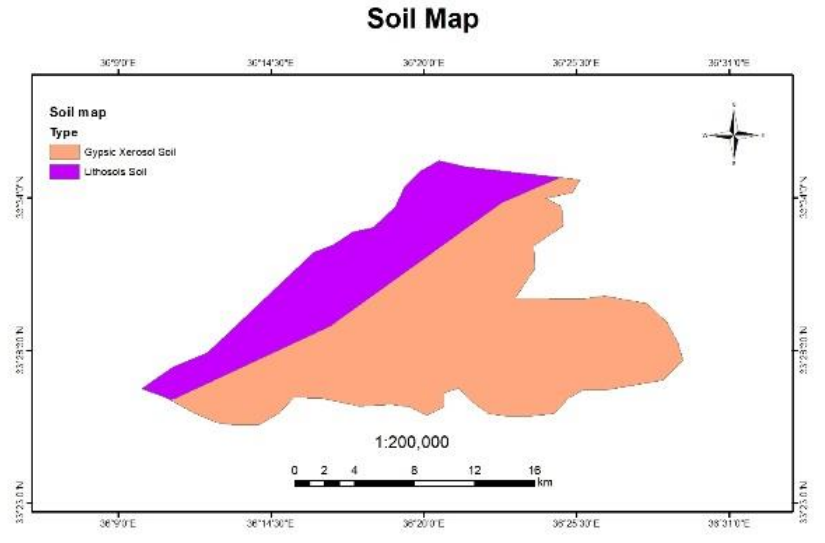

Figure 8: Soil map

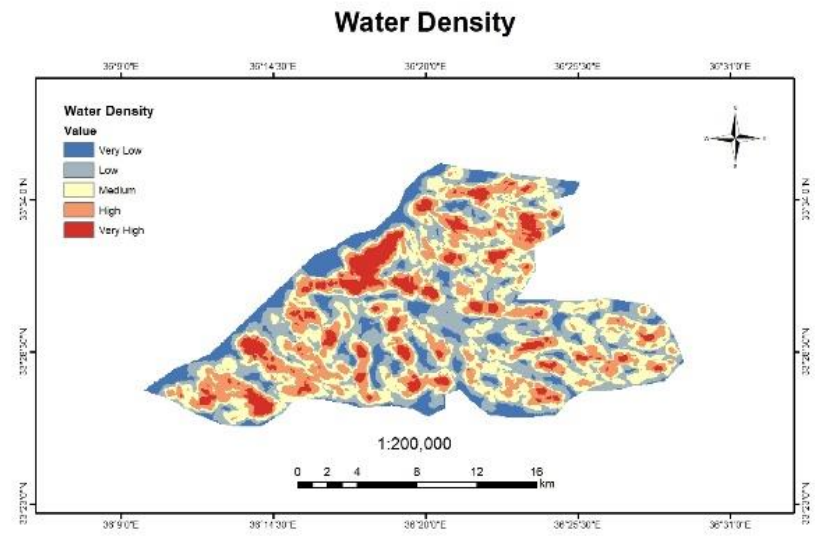

Figure 9: Density from bodies

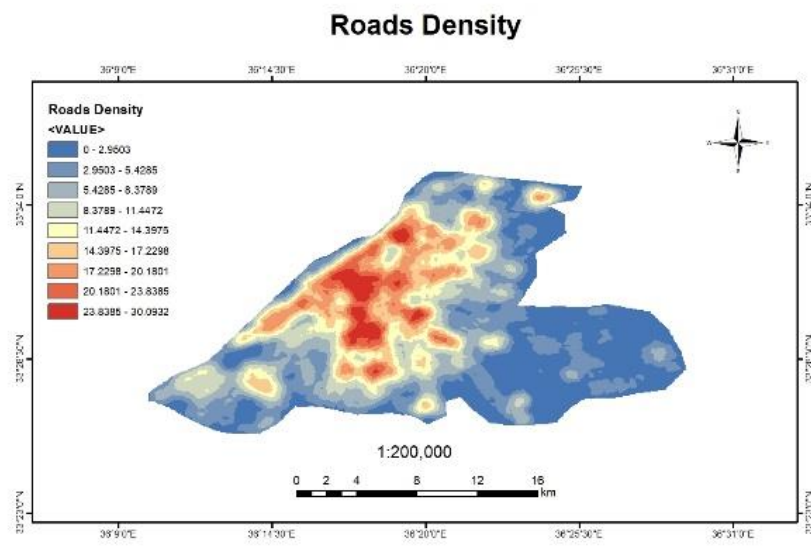

Figure 10: Density from Road Network

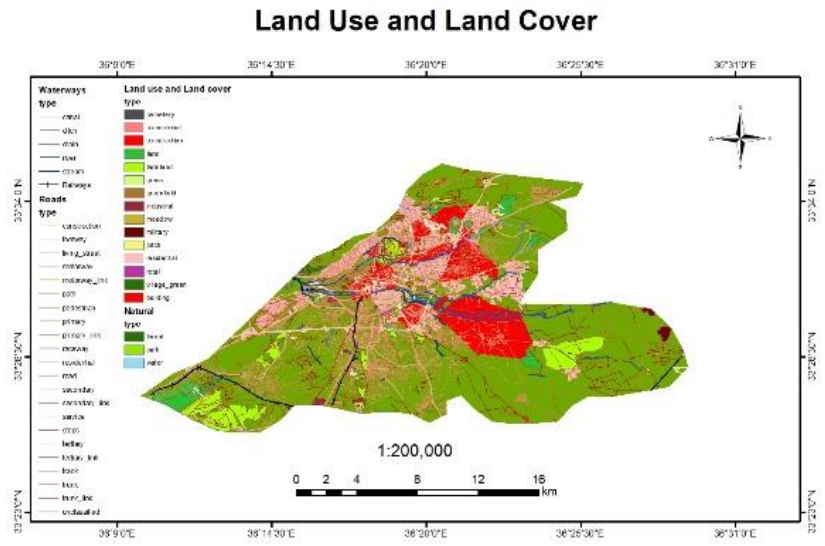

Figure 11: Land use

The results of the AHP analysis were classified into five classes in terms of suitability for reconstruction: not suitability, low suitability, moderate suitability, high suitability, very high suitability. Is shown in figure 12 .

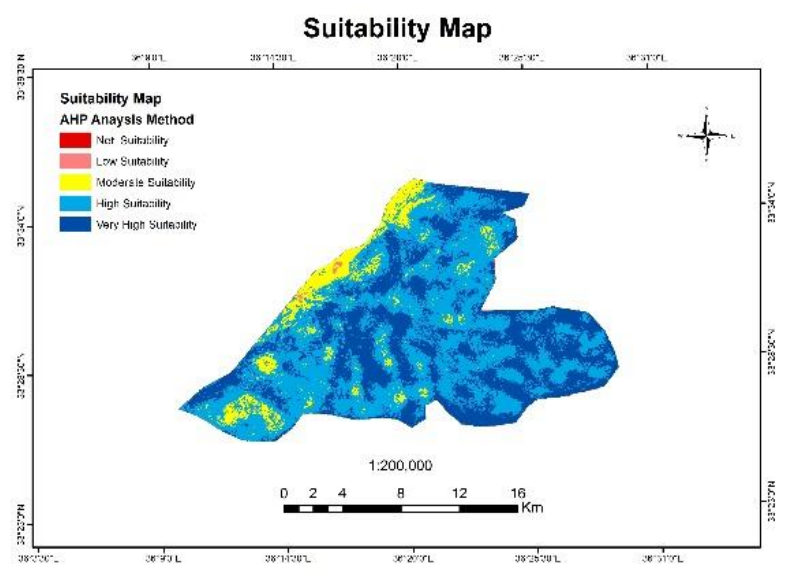

Figure 12: Suitability map by AHP analysis

\section{CONCLUSION}

In this study, the AHP analysis method was used to determine Damascus's most suitable reconstruction areas. Six criteria were used: slope, heights, soil, water network, road network, and land use map. Calculated the consistency ratio (CR), this method is based on the collection of all the criteria after multiplying weights in rating; the study area was classified into five classes in terms of the suitability for The Use AHP within GIS for destructed areas in Damascus, Syria reconstruction: not suitability $2 \%$, low suitability $13 \%$, moderate suitability $20 \%$, high suitability $24 \%$, very high suitability $41 \%$. Is shown in figure 13 . 


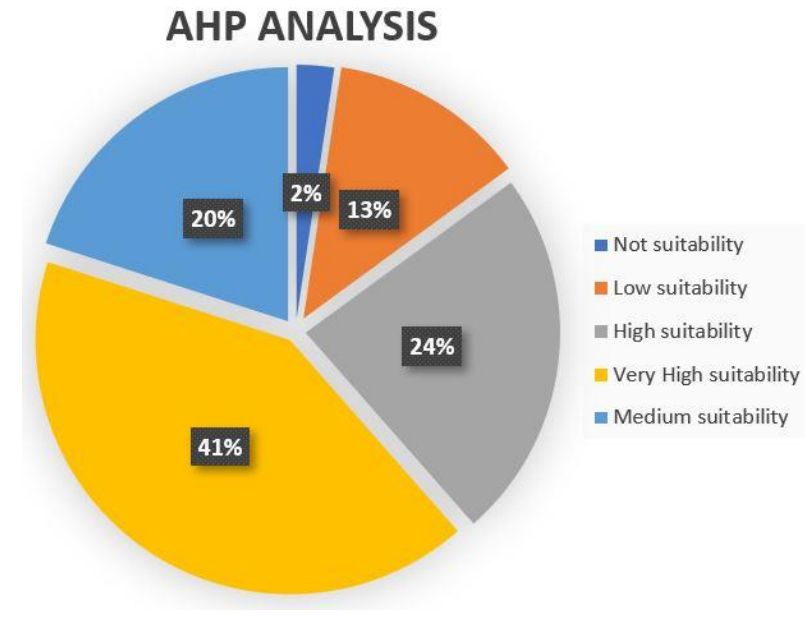

Figure 13: Suitability Percentage

\section{REFERENCES}

Achour, Y., Boumezbeur, A., Hadji, R., Chouabbi, A., Cavaleiro, V., \& Bendaoud, E. A. 2017. Landslide susceptibility mapping using analytic hierarchy process and information value methods along a highway road section in Constantine, Algeria. Arabian Journal of Geosciences, 10(8), 194.

Akıncı, H., Özalp, A. Y., \& Turgut, B. 2013. Agricultural land use suitability analysis using GIS and AHP technique. Computers and electronics in agriculture, 97, 71-82.

Arraf, F. 2019. Causes of Decreasing Water Balances in the Barada Awaj (Damascus) Drainage Basin until the Uprising in Syria. Open Journal of Modern Hydrology, 9(4), 143-160.

Bozdağ, A., Yavuz, F., \& Günay, A. S. 2016. AHP and GIS based land suitability analysis for Cihanbeyli (Turkey) County. Environmental Earth Sciences, 75(9), 813.

Del Moral, R., \& Walker, L. R. 2007. Environmental disasters, natural recovery and human responses. Cambridge: Cambridge University Press.

European Space Agency. Sentinel-2 MSI Technical Guide 2017. Available online: https://earth.esa.int/web/ sentinel/technical-guides/sentinel-2-msi (accessed on 1 October 2019).

European Space Agency. Sentinel-2 User Handbook. ESA Standard Document Paris, France 2015. Available online: https://sentinel.esa.int/documents/247904/685211/Sentinel2_User_Handbook (accessed on 1 October 2019).

Jafari, S., \& Zaredar, N. 2010. Land Suitability Analysis using Multi AttributeDecision Making Approach. International journal of environmental science and development, 1(5), 441.

Leonard, S., 2018. Emerging Trends in Crisis Management: Usability, Earth Observation and Disaster Management. In Crisis Management-Theory and Practice. IntechOpen.

Mendas, A., \& Delali, A. 2012. Integration of MultiCriteria Decision Analysis in GIS to develop land suitability for agriculture: Application to durum wheat cultivation in the region of Mleta in Algeria. Computers and Electronics in Agriculture, 83, 117-126.

REACH. Syrian Cities Damage Atlas. Eight Year Anniversary of The Syrian Civil War. Available online. 16 March 2019.

Reduction, D. R. 2009. UNISDR terminology on disaster risk reduction.

Sarvar, H., Amini, J., \& Laleh-Poor, M. 2011. Assessment of risk caused by earthquake in region 1 of Tehran using the combination of RADIUS, TOPSIS and AHP models. Journal of Civil Engineering and Urbanism, 1(1), 39-48.

Sentinel's Scientific Data Hub. Available online: https://scihub.copernicus.eu/ (accessed on 19 September 2019).

Tairi, A., Elmouden, A., \& Aboulouafa, M. 2019. Soil Erosion Risk Mapping Using the Analytical Hierarchy Process (AHP) and Geographic Information System in the Tifnout-Askaoun Watershed, Southern Morocco. Eur. Sci. J, 15, 1857-7881. 